\title{
Perceived stigma and associated factors among people with epilepsy at Gondar University Hospital, Northwest Ethiopia: a cross-sectional institution based study
}

\author{
Berhanu Boru Bifftu ${ }^{1}$, Berihun Assefa Dachew², Bewket Tadesse Tiruneh ${ }^{1}$
}

1. University of Gondar College of Medicine and Health Science, Department of Nursing, Gondar, Ethiopia.

2. University of Gondar, College of Medicine and Health Sciences, Department of Epidemiology and Biostatistics, Gondar, Ethiopia.

\begin{abstract}
Background: Epilepsy is the world's most common neurological disorder, affecting approximately 69 million people worldwide. Perceived stigma affects many domains of the lives of people with epilepsy. However, in Ethiopia there is dearth of study on perceived stigma specifically among people with epilepsy.

Objective: To assess the prevalence of perceived stigma and associated factors among people with epilepsy (PWE) attending the outpatient department of the University of Gondar hospital, Northwest Ethiopia, 2014.

Methods: Institution based quantitative cross - sectional study was employed among 408 individuals people with epilepsy. Single population proportion formula was used utilized to calculate sample size. The participants were selected using systematic random sampling technique. Perceived stigma was measured using by the modified Family Interview Schedule (FIS) tool. Binary logistic regression analysis and adjusted odds ratio with 95\% confidence interval were used to identify the associated factors with perceived stigma..

Results: Overall, the prevalence of perceived stigma was found to be $71.6 \%$. Marital status [single (AOR $=0.23$, CI: $0.25,0.90)$, widowed $(\mathrm{AOR}=0.37$, CI: $0.15,0.90)$ duration of illness $[2-5$ years $(\mathrm{AOR}=4.38, \mathrm{CI}: 1.98,9.62,6-10$ years $(\mathrm{AOR}=4.29, \mathrm{CI}: 1.90,9.64, \geq 11$ years $(\mathrm{AOR}=4.31, \mathrm{CI}: 1.84,10.00)$ and seizure frequency of $[1-11$ per year $(\mathrm{AOR}=2.34$, CI:2.21,3.56), $\geq 1$ per month (AOR $=5.63$, CI:3.42,10.32)] were factors associated with perceived stigma.

Conclusion: Overall, the prevalence of perceived stigma was found to be high. Marital status, long duration of illness and seizure frequency were factors associated with perceived stigma.

Keywords: Northwest Ethiopia, epilepsy, perceived stigma

DOI: http://dx.doi.org/10.4314/ahs.v15i4.21

Cite as: Bifftu BB, Dachew BA, Tiruneh BT. Perceived stigma and associated factors among people with epilepsy at Gondar University Hospital, Northwest Ethiopia: a cross-sectional institution based study. Afri Health Sci. 2015;15(4):1211-9. http://dx.doi.org/10.4314/abs. v15i4.21
\end{abstract}

\section{Background}

Epilepsy is the world's most common neurological disorder, affecting approximately 69 million people worldwide, and the majority of whom $90 \%$ live in resource-poor countries ${ }^{1}$.

The prevalence of epilepsy in Africa ranges from 2.2 to 58 per 1000 population and it is the second or third most common reason for consultation and hospitalization ${ }^{2}$.

Unlike many other chronic diseases such as hypertension or diabetes, the symptoms and signs of epilepsy

\author{
Corresponding author: \\ Berhanu Boru Bifftu, \\ University of Gondar \\ College of Medicine and Health Science, \\ Department of Nursing, Gondar, Ethiopia. \\ Email: berhanuboru@gmail.com, \\ P.O.Box: 196, Tel.no:+251-911535970
}

are peculiarly unhidden, unpredictable and not easy to understand by the terrified watchers, that is why and what seemed to be the reason for a normal person to behave in a very strange manner, which makes the seizures look like confusion against the cultural norms ${ }^{3}$. And people's belief that epilepsy is contagious and thus hesitate to help or touch the person who has fallen during a seizure. Thus, those suffering from epilepsy are stigmatized and ostracized in the belief that their condition is a demonic possession and believed to be contagious consequently lead epileptic patients to develop different psycho-social problem such as perceived stigma and psychiatric illness which affect epileptic patients more than the seizure itself $\mathrm{f}^{1-5}$.

Stigma is typically a social process, experienced or anticipated and characterized by exclusion, rejection and blame or devaluation about a person or group ${ }^{6}$. Literature revealed that, stigma occurs at three different levels namely the macro, meso and micro level. Institutional stigma refers to the stigma that exists at system (macro) level and was defined as the rules, policies, and proce- 
dures of private and public entities in positions of power that restrict the rights and opportunities of people with disabling conditions. Public stigma occurs at the group (meso) level and can be defined as the phenomenon of large social groups endorsing stereotypes about and acting against a stigmatized group ${ }^{7}$. Micro level stig$\mathrm{ma}$ is the stigma which exists at the individual level. It can be divided into perceived public stigma/stereotype awareness (participants' beliefs that in general people with epilepsy are stigmatized in society), personal stig$\mathrm{ma} /$ stereotype agreement (participants' personal beliefs about the illness) and self-stigma is internalization of perceived public stigma and applies to corresponding stereotypes and prejudices to the self ${ }^{8}$.

Although the reasons for stigmatization are not consistent across communities or cultures, barriers such as stigma against people with epilepsy prevents them from accessing and receiving the help they need to get and stay well ${ }^{1,2}$. Thus, most of the persons with epilepsy reach proper health facilities very late with neuron-psychiatric ${ }^{9,10}$. Different literature reported that perceived stigma affects many domains of the lives of people with epilepsy such as poor self- esteem, poor social relationships, lack of willingness to seek help or Antiepileptic Drugs (AEDs), difficulties of access to housing \& unemployment $t^{3,4,10-12}$. Many studies from the Western world have reported on stigmatization of people with epilepsy and its negative consequences ${ }^{13,14}$. The few studies conducted in Africa also reported the widespread existence of stigma among epileptic patients ${ }^{11}$.

In Ethiopia, epilepsy is a a major public problem, which affects about 29.5 per 1000 population ${ }^{15}$

The existing studies revealed that people with epilepsy (PWE) suffer from a number of social, psychological and physical problems. For example a study conducted by Shibru B. in Ethiopia revealed that $60 \%$ of the study participants face different social, psychological and physical problems as a result of their illness such as stigma by $24 \%$, inability to find partner by $31 \%$, problems with education by $17 \%$, and problems of employment by $9 \%$, serious physical injuries by $9 \%$ and $10 \%$ suffered from burns ${ }^{16}$. In Ethiopia there is a widespread belief about the cause of epilepsy as demon possessions, bewitchment by evil spirits, ancestors' spirits or the evil eyes. As a result, affected individuals and/or their families often seek help from religious and traditional healers rather than health facilities. Regarding perceived stigma there is no published study among PWE. The only published study included both the patient and their

African Health Sciences Vol 15 Issue 4, December 2015 family member. This study revealed that $81 \%$ of the study subjects experienced stigma ${ }^{12}$. Because of these problems ${ }^{4,12,16}$, in a recently released Ethiopian Mental Health Strategic Plan, was suggested that strategic emphasis be given to the care of epileptic patients as they require special consideration ${ }^{17}$.

However, the available studies from Western and some African country demonstrated high perceived stigma. In Ethiopia there is dearth of study on perceived stigma specifically among people with epilepsy. Therefore, looking at the diverse problem related to perceived stigma, assessing the prevalence and predictors of perceived stigma that are important and hopefully design some effective treatment programs for the management and prevention of its consequences. Thus, the main purpose of this study was to assess the prevalence and associated factors of perceived stigma among people with epilepsy at the University of Gondar hospital, Northwest Ethiopia, 2014.

\section{Methods \\ Study design}

Institution based cross-sectional study design was used.

\section{Study area and period}

The study was conducted at the University of Gondar hospital from January first to end of February,2014. The University of Gondar hospital is located in Gondar town, 748 kilometers away from the capital city of Ethiopia, Addis Ababa. Gondar University hospital serves about 5 million people in the catchment area. It has 400 beds in five different inpatient departments and 14 wards.

\section{Participants}

Participants of this study were individuals with epilepsy receiving follow-up care at the outpatient department of the University of Gondar hospital. Single population proportion formula (with a 5\% margin of error, 95\% confidence level and 50\% proportion) was used to calculate sample size; and it was found to be 422 (including $10 \%$ non-response rate). The total number of patients who visited the hospital for the last 12 months were taken from patient records and then the average number of patients per day calculated and participants were selected by systematic random sampling technique. All patients consented to participate in the study. Only individuals with a clinical diagnosis of epilepsy returning for follow-up care with an age greater than or equal to 18 years were selected. Individuals with epilepsy who were critically ill (couldn't give a response), who were unable to speak and hear were excluded from the study. 


\section{Instruments}

For the assessment of perceived stigma the modified Family Interview Schedule (FIS) developed by World Health Organization was used. These questionnaires were previously used in Ethiopia among similar study subjects and their family. FIS has 14 stigma items, but only thirteen stigma questions was used from previous study to reduce redundancy after translation into Amharic (local language). In this study we also used the thirteen stigma questions ${ }^{12}$. Each stigma item was rated on a 4-point scale from "not at all" (rated $=0)$ to "a lot "(rated=3) with respect to perceived stigma. The presence of perceived stigma was defined by the respondent's score of at least one positive item on the thirteen FIS items ${ }^{18}$. In this study, FIS had an internal consistence of Cronbach's alpha 0.890 for the total score.

For the assessment of depression Beck Depression Inventory (BDI-II) was used. BDI is one of the most widely used self-report measures of depression. It is a reliable and valid measure of depression in a range of cultural groups and has been validated with psychiatric and non- psychiatric populations in most of the countries including Africa. It consists of 21 items, and each of its items describes a specific behavioural manifestation of depression. A more recent version of the instrument (BDI-II) was used to correspond to DSMIV criteria for depression. BDI-II used for screening of recent (during past two weeks) depression symptoms in persons with epilepsy. Each statement is scored on a 4-point scale $(0-3)$ and a total score is obtained by summing the ratings for each statement. The prevalence of depression was defined using a cutoff point $\geq 10$ on BDI-IIBDI-21 as having depression. A score from 0 - 9 is considered to be within the normal range or asymptomatic; a score of 10 - 18 indicates mild-to-moderate depression; a score of 19 - 29 indicates moderate-to-severe depression and a score of 30 or more indicates extremely severe depression ${ }^{19,20}$. The questionnaires were translated into Amharic (local language) by an Amharic speaking linguist. The back-translation was performed by mental health specialist into English and then a consensus version was developed in a group discussion involving the research team. This was compared with the original version, and confirmed to be satisfactory for use. The questionnaires were tested on 21 patients to make it easier for the participants to understand and complete. In this study, BDI-II had an internal consistence of Cronbach's alpha 0.855 for the total score.
For the assessment of stress perceived stress scale (PSS) was used. The Perceived Stress Scale (PSS) is the most widely used psychological tool for measuring the perception of stress. It is a measure of the degree to which situations in one's life are appraised as stressful. The questions in the PSS asked about the feelings and thoughts of the patients during the past month. Each item is rated on a 5 -point scale ranging from never (0) to almost always (4). Positively worded items are reverse scored, and the ratings are summed, with higher scores indicating more perceived stress.PSS-10 scores are obtained by reversing the scores on the four positive items: For example, $0=4,1=3,2=2$, etc. and then summing across all 10 items. Items 4, 5, 7, and 8 are the positively stated items. The presence of perceived stress was defined using a cutoff point $\geq 20$ on PSS-10. PSS had an internal consistence of Cronbach's alpha for the total score of PSS $=0.793$ (21). Furthermore, we asked one question on antiepileptic medication adherence. The antiepileptic medication adherence question asked about history of non-adherence with antiepileptic medications with yes/ no response. Specifically, we asked "Have you ever discontinued your antiepileptic medication?

\section{Data collection and analysis}

Data was collected by face-to-face interview using a semi-structured questionnaire with the Amharic version of the socio-demographic, clinical factors, BDI-II, PSS and FIS questionnaires.

Data was coded and entered into EPI info version 3.5.3 statistical software and then exported to SPSS windows version 16 program for analysis. Descriptive statistics (frequencies, tables, percentages, means and standard deviation) were used for the socio-demographic, clinical variables, BID-II, PSS including individual's response to FIS.Binary logistic regression and adjusted odds ratio with $95 \%$ confidence interval were used to identify the associated factors of outcome variable.

All factors with a p-value $<0.2$ in the bivariate logistic regression were entered into the multivariate model. Statistical significance was accepted at the 5\% level (p $<0.05)$.

\section{Ethical consideration}

The study proposal was initially approved by the ethical review board of The University of Gondar. A formal letter of permission was obtained from the University of Gondar hospital and submitted to the respective out- 
patient department. The information about the study was given to the participants. Verbal and then written informed consent was sought from each participant who agreed to participate in the study and full filled the inclusions criteria. Only anonymous data collected in private rooms.

\section{Results}

A total of 408 participants participated in this study with a $96.7 \%$ response rate. Fourteen questionnaires were not filled properly.
Socio-demographic and clinical characterstics of the participants

The majority of the participants were men 257 (63\%). The mean age of the participants was $28.63 \pm 9.70$ years. One hundred and ninety eight $(48.5 \%)$ of the participants were primary educated, $375(91.9 \%)$ were Orthodox Christian and 247 (60.5\%) were married. Three hundred and eighty seven $(94.9 \%)$ of the participants were Amhara in Ethnicity. Out of 408 participants, 241 $(59 \%)$ were self-employed and $216(52.9 \%)$ were living in urban areas.

Table 1. Distribution of participant by their socio-demographic and clinical characteristics at University of Gondar Hospital,2014 (n=408)

\begin{tabular}{|c|c|c|}
\hline Characteristics & Number & Percent \\
\hline $\begin{array}{l}\text { Sex } \\
\text { Male } \\
\text { Female }\end{array}$ & $\begin{array}{l}257 \\
151\end{array}$ & $\begin{array}{l}63 \\
37\end{array}$ \\
\hline $\begin{array}{l}\text { Age } \\
</=24 \\
25-34 \\
35-44 \\
>=45\end{array}$ & $\begin{array}{l}166 \\
125 \\
87 \\
30\end{array}$ & $\begin{array}{l}40.7 \\
30.6 \\
21.3 \\
7.4\end{array}$ \\
\hline $\begin{array}{l}\text { Educational status } \\
\text { Can't read and write } \\
\text { Primary } \\
\text { Secondary } \\
\text { College and above } \\
\end{array}$ & $\begin{array}{l}117 \\
198 \\
51 \\
42 \\
\end{array}$ & $\begin{array}{l}28.7 \\
48.5 \\
12.5 \\
10.3 \\
\end{array}$ \\
\hline $\begin{array}{l}\text { Religion } \\
\text { Orthodox } \\
\text { Muslim }\end{array}$ & $\begin{array}{l}375 \\
33\end{array}$ & $\begin{array}{l}91.9 \\
8.1\end{array}$ \\
\hline $\begin{array}{l}\text { Marital status } \\
\text { Married } \\
\text { Single } \\
\text { Divorced/Widowed }\end{array}$ & $\begin{array}{l}247 \\
119 \\
42\end{array}$ & $\begin{array}{l}60.5 \\
28.2 \\
10.3\end{array}$ \\
\hline $\begin{array}{l}\text { Ethnicity } \\
\text { Amhara } \\
\text { Tigre }\end{array}$ & $\begin{array}{l}387 \\
21\end{array}$ & $\begin{array}{l}94.9 \\
5.1\end{array}$ \\
\hline $\begin{array}{l}\text { Employment } \\
\text { Government } \\
\text { Private } \\
\text { Student } \\
\text { Unemployed }\end{array}$ & $\begin{array}{l}28 \\
241 \\
66 \\
73 \\
\end{array}$ & $\begin{array}{l}6.9 \\
59 \\
16.2 \\
17.9 \\
\end{array}$ \\
\hline $\begin{array}{l}\text { Residence } \\
\text { Rural } \\
\text { Urban }\end{array}$ & $\begin{array}{l}192 \\
216 \\
\end{array}$ & $\begin{array}{l}47.1 \\
52.9 \\
\end{array}$ \\
\hline $\begin{array}{l}\text { Social support } \\
\text { High } \\
\text { Moderate } \\
\text { Low }\end{array}$ & $\begin{array}{l}250 \\
94 \\
64\end{array}$ & $\begin{array}{l}61.3 \\
23 \\
15.7\end{array}$ \\
\hline $\begin{array}{l}\text { Perceived stress } \\
\text { Low } \\
\text { High }\end{array}$ & $\begin{array}{l}190 \\
218 \\
\end{array}$ & $\begin{array}{l}46.6 \\
53.4 \\
\end{array}$ \\
\hline $\begin{array}{l}\text { Duration of the disease } \\
<1 \\
2-5 \\
6-10 \\
>=11\end{array}$ & $\begin{array}{l}40 \\
144 \\
118 \\
106\end{array}$ & $\begin{array}{l}9.8 \\
35.3 \\
28.9 \\
26\end{array}$ \\
\hline $\begin{array}{l}\text { Seizure frequency per year } \\
0 \\
1-11 / \text { year } \\
>=1 / \text { month }\end{array}$ & $\begin{array}{l}85 \\
293 \\
30\end{array}$ & $\begin{array}{l}20.8 \\
71.8 \\
7.4\end{array}$ \\
\hline $\begin{array}{l}\text { Therapy(number of drug) } \\
\text { Mono-therapy } \\
\text { Poly-therapy }\end{array}$ & $\begin{array}{l}310 \\
98\end{array}$ & $\begin{array}{l}76 \\
24\end{array}$ \\
\hline $\begin{array}{l}\text { Difficulties of adherence to AEDs } \\
\text { Yes } \\
\text { No }\end{array}$ & $\begin{array}{l}134 \\
274\end{array}$ & $\begin{array}{l}32.8 \\
67.2\end{array}$ \\
\hline
\end{tabular}


The mean age of disease onset was $19.80 \pm 10.15$ years. The mean duration of disease was $7.99 \pm 5.98$ years. Out of 408 patients, 293 (71.8\%) had seizure frequency range from 1-11 times per year. Three hundred and ten $(76 \%)$ of the participants were treated with one AED (mono- therapy) and $264(67.2 \%)$ had a history of non-adherence to AEDs (Table 1).

\section{Prevalence of perceived stigma}

Overall, the prevalence of perceived stigma was found to be $71.6 \%$. Regarding the proportion of perceived stigma toward each item, $156(38.2 \%)$ of the participants agreed with the item "Felt guilt or depression because of epilepsy (Table 2).

Table 2 Proportion of perceived stigma response of participants to each item at University of Gondar Hospital, $1014(\mathrm{n}=\mathbf{4 0 8})$

\begin{tabular}{|c|c|c|c|c|c|}
\hline & Scale & Not at all & Sometimes & Often & A lot \\
\hline 1 & Worried to be treated differently. & $285(69.9)$ & $66(16.2)$ & $45(11)$ & $12(2.9)$ \\
\hline 2 & $\begin{array}{l}\text { Worried people would know out } \\
\text { about it. }\end{array}$ & $282(69.1)$ & $66(16.2)$ & $48(11.8)$ & $12(2.9)$ \\
\hline 3 & Felt the need to hide this fact. & $276(67.6)$ & $63(15.4)$ & $57(14)$ & $12(2.9)$ \\
\hline 4 & $\begin{array}{l}\text { Helping other people to understand } \\
\text { what it is like to have a family } \\
\text { member with psychiatric problems. }\end{array}$ & $279(68.4)$ & $105(25.7)$ & $18(4.4)$ & $6(1.5)$ \\
\hline 5 & Worried to be avoided & $257(63)$ & $87(21.3)$ & $43(10.5)$ & $21(5.1)$ \\
\hline 6 & $\begin{array}{l}\text { Explaining to others that -(name)- } \\
\text { isn't like their Picture of "crazy" } \\
\text { people. }\end{array}$ & $306(75)$ & $84(20.6)$ & $15(3.7)$ & $3(0.7)$ \\
\hline 7 & $\begin{array}{l}\text { Worried that people would blame } \\
\text { you for his or her problems. }\end{array}$ & $304(74.5)$ & $59(14.5)$ & $36(8.8)$ & $9(2.2)$ \\
\hline 8 & $\begin{array}{l}\text { Worried that a person looking to } \\
\text { marry would be reluctant to marry } \\
\text { into your family. }\end{array}$ & $315(77.2)$ & $48(11.8)$ & $30(7.4)$ & $15(3.7)$ \\
\hline 9 & Worried about taking him or her out. & $318(77.9)$ & $75(18.4)$ & $9(2.2)$ & $6(1.5)$ \\
\hline 10 & $\begin{array}{l}\text { Felt ashamed or embarrassed about } \\
\text { it. }\end{array}$ & $276(67.6)$ & $78(19.1)$ & $42(10.3)$ & $12(2.9)$ \\
\hline 11 & $\begin{array}{l}\text { Sought out people who also have a } \\
\text { family member who has had } \\
\text { psychiatric problems. }\end{array}$ & $345(84.6)$ & $42(10.3)$ & $12(2.9)$ & $3(0.7)$ \\
\hline 12 & $\begin{array}{l}\text { Felt guilt or depression because of } \\
\text { it. }\end{array}$ & $252(61.8)$ & $102(25)$ & $45(11)$ & $9(2.2)$ \\
\hline 13 & $\begin{array}{l}\text { Felt that somehow it might be your } \\
\text { fault. }\end{array}$ & $282(69.1)$ & $90(22.1)$ & $21(5.1)$ & $15(3.7)$ \\
\hline
\end{tabular}

\section{Factors associated with perceived stigma}

From the bivariate analysis: age, sex, marital status, employment, perceived stress, the onset of the illness, duration of the illness, seizure frequency, poly-therapy, and depression were factors associated with perceived stigma at $\mathrm{p}$-value $<0.20$. Individual factors that were significant at this level were entered in to a subsequent multivariate analysis.
On the other hand; religion, ethnicity, residence, educational status, social support, and adherence to AEDs were not associated with perceived stigma at p-value $<$ 0.20 and thus excluded from further analysis.

From the multivariate analysis; marital status [single $($ AOR $=0.23$, CI: 0.25, 0.90), widowed $($ AOR $=0.37, \mathrm{CI}: 0.15,0.90)$, duration of illness $[2-5$ years $(\mathrm{AOR}=4.38, \mathrm{CI}: 1.98,9.67), 6-10$ years $(\mathrm{AOR}=4.29$, 
CI:1.90,9.68), $\geq 11$ year $(\mathrm{AOR}=4.31, \mathrm{CI}: 1.86,10.00)$, seizure frequency of $[1-11$ per year $(\mathrm{AOR}=2.34$,
CI:2.21,3.56), $\geq 1$ per month (AOR = 5.63, CI:3.42,10.32)], were factors statistically significant with perceived stigma at p-value $<0.05$ (Table 3).

Table 3: Factors associated with perceived stigma (bivariate and multivariate) analysis, at the University of Gondar Hospital,2014(n=408).

\begin{tabular}{|c|c|c|c|c|c|}
\hline \multirow[t]{2}{*}{ Erplasatory variables } & \multicolumn{2}{|c|}{ Perceived sdigma } & \multirow[t]{2}{*}{ COR(954)CD } & \multirow[t]{2}{*}{ AOR(956)CI) } & \multirow[t]{2}{*}{ P-ralue } \\
\hline & $\operatorname{Yes} \mathbf{N}(46)$ & No $\mathbf{N}\left(\mathbf{c}_{6}\right)$ & & & \\
\hline \multicolumn{6}{|l|}{ Age } \\
\hline $18-24$ & $133(33.1)$ & $31(7.6)$ & $2.90(1.27,6.65)$ & & \\
\hline $25-34$ & $38(21.0)$ & $37(9.1)$ & $1.53(0.70,3.62)$ & & \\
\hline $35-44$ & $51(12.5)$ & $36(8.8)$ & $0.94(0.41,2.20)$ & & \\
\hline$=45$ & $18(4.4)$ & $12(2.9)$ & 1 & & \\
\hline \multicolumn{6}{|l|}{ Set } \\
\hline Men & $175(429)$ & $82(20.1)$ & $0.62(0.39,0.99)$ & & \\
\hline Woman & $117(287)$ & $34(83)$ & 1 & & \\
\hline \multicolumn{6}{|l|}{ Marital states } \\
\hline Marriad & $105(480)$ & $52(13)$ & 1 & 1 & 1 \\
\hline Single & $70(17.5)$ & $49(12.3)$ & $0.33(0.24,0.61)$ & $0.23(0.25,0.90)^{*}$ & 0.023 \\
\hline Diverred widewsed & $21(53)$ & $12(3)$ & $0.47(022.101)$ & $0.37(0.15,0.90) *$ & 0028 \\
\hline \multicolumn{6}{|l|}{ Employmest } \\
\hline Govemment & $15(37)$ & $13(32)$ & 1 & & \\
\hline Privase & $163(40)$ & $78(19.1)$ & $1.81(0.82 .3 .99)$ & & \\
\hline Studantr & $57(14)$ & $9(2.2)$ & $5.45(107,15.26)$ & & \\
\hline \multicolumn{6}{|l|}{$\begin{array}{l}\text { Uneuployed } \\
\text { Perceived stross }\end{array}$} \\
\hline High & $169(41.4)$ & $49(12)$ & $1.83(1.22,2.90)$ & & \\
\hline tow & $123(301)$ & $67(164)$ & 1 & & \\
\hline \multicolumn{6}{|l|}{ Depression } \\
\hline Yes & $141(34.6)$ & $43(10.5)$ & $159(1.02 .2 .46)$ & & \\
\hline No & $151(37)$ & $73(179)$ & 1 & & \\
\hline \multicolumn{6}{|c|}{ Age at onset of the illness in year } \\
\hline$<6$ & $9(2.2)$ & $9(2.2)$ & $1.01(0.01,4.99)$ & & \\
\hline $6-11$ & $36(8.8)$ & $9(2.2)$ & $2.66(1.04 .6 .85)$ & & \\
\hline $12-17$ & $0420.6)$ & $20(6.9)$ & $2.00(0.96,+.17)$ & & \\
\hline $18-24$ & $81(19.9)$ & $31(0.6)$ & $1.74(0.84 .3 .60)$ & & \\
\hline $25-34$ & $46(11.3)$ & $30(7.4)$ & $1.02(0.48,2.17)$ & & \\
\hline$>35$ & $27(0.0)$ & $18(4,4)$ & 1 & & \\
\hline \multicolumn{6}{|c|}{ Duration of the illness in year } \\
\hline 1 & $21(5.1)$ & $19(4.7)$ & 1 & 1 & \\
\hline 2.5 & $111(272)$ & $33(8.1)$ & $3.04(1.46,6.33)$ & $4.38(1.98 .9 .67)$. & 0.001 \\
\hline $0-10$ & $88(21.0)$ & $50(7.4)$ & $2.05(1.20,5.00)$ & $4.29(1.90 .9 .08)$ & $<0.001$ \\
\hline$\geqslant 11$ & $72(17.6)$ & $34(8.3)$ & $1.90(0.91,4.03)$ & $431(1.86,10.00) \cdot$ & 0.002 \\
\hline \multicolumn{6}{|c|}{ Seizare frequency per year } \\
\hline 0 & $39(9.6)$ & $46(113)$ & 1 & 1 & \\
\hline 1-11year & $232(569)$ & $\sigma 1(15)$ & $4.49(2.09,7.48)$ & $234(2.24 .3 .56)^{*}$ & 0.022 \\
\hline$\geq 1 /$ weonth & $21(5.1)$ & $9(2.2)$ & $2.75(1.13,6.70)$ & $5.63(3.42,10.32) \cdot$ & 0.000 \\
\hline \multicolumn{6}{|c|}{ Iberapy (uumber of drug takes) } \\
\hline Moso-thacapy & $217(532)$ & $03(22.8)$ & 1 & & \\
\hline Poly-therapy & $75(13.4)$ & $23(5.0)$ & $1.19(1.71 .9 .62)$ & & \\
\hline
\end{tabular}

\section{Discussion}

The aim of this study was to assess the prevalence of perceived stigma and associated factors among people with epilepsy at the University of Gondar hospital. Overall, the prevalence of perceived stigma was found to be $71.6 \%$. This result is similar with the study carried out in Benin $(68.7 \%)^{11}$. The results of this study sup- port the study carried out elsewhere as perceived stigma is a common problem among epileptic patients.

The result of this study $(71.6 \%)$ is lower as compared to the study carried out in Iran (86\%) among 100 epileptic patients using Jacoby's stigma scale ${ }^{14}$ and the study conducted in Ethiopia (81\%) among epileptic patient and their family member using the same tool ${ }^{12}$. The possi- 
ble explanations for the variation may be due to use of different tools, geographical areas, sample size and cultures of the study subject with the Iranian and for the Ethiopia study it may be due to the addition of family member as a study subject and the study setting. This may indicate that family members of the patient also suffer more perceived stigma. Study shows the moral weight attached to epilepsy not only applied to the affected person, but also threatened family members through a process of courtesy stigma because of fear of family disgrace, people with epilepsy were typically kept at home and their diagnosis was kept secret ${ }^{22}$.

In contrast, the prevalence of perceived stigma in this study is higher than the study carried out in ten European countries (Belgium, France, Germany, Holland, Italy, Poland, Portugal, Spain, Turkey, and the U.K.) that shows overall $17 \%$ of perceived stigma ${ }^{13}$, another study from Eastern Europe (Estonia) revealed that $51 \%$ of the study subject reported perceived stigma ${ }^{23}$ and in Ethiopia $(41.3 \%)^{24}$. The possible explanations for the variation may be due to use of different tools, geographical areas sample size and cultures of the study subject.

Regarding the associated factors, those patients with single marital status were about seventy seven times $[(\mathrm{AOR}=0.23, \mathrm{CI}: 0.25,0.90)$ less likely to develop perceived stigma and those divorced/widowed were about sixty three times(AOR $=0.37, \mathrm{CI}: 0.15,0.89)]$ less likely to develop perceived stigma than those patients who are married. These results were consistent with the previous study ${ }^{11}$. This is due to the fact that those patients who are married might be concealing their illness from their spouse before marriage because of fear from unfair discrimination in various respects. A Study showed that people with epilepsy usually do not inform their spouses about their illness before marriage because of fear from its consequences and impacts on marriage negotiations (perceived stigma) ${ }^{25}$. Another study that supports this explanation also showed that PWE's who disclosed their illness before marriage might not suffer from serious social discrimination in conjugal life forever ${ }^{26}$. However; expressing their feeling, stress, and other issues to their partner helps them to reduce perceived stigma, those patient who are married may fear social stigma, fear of other people's reactions and shame which isolated themselves as means of preventing themselves from perceived social stigma. As report- ed by study subjects a problem in marriage was caused because of different reason. For example, the hereditary nature of epilepsy accounts for 53.9 percent of the problem, fear of contamination accounts for 23.8 percent, inviting bad luck account for 15.8 percent and fear of seizure account for 6.5 percent $^{27}$. In contrary to this finding a study carried out in Boston, Massachusetts, and Atlanta, Georgia, using a perceived stigma questionnaire also revealed that those participants who were never married, or divorced reported greater stigma ${ }^{28}$.

Those patients who had 2-5 year duration of illness were more than four times [(AOR $=4.38, \mathrm{CI}: 1.98,9.67)$ ] more likely to develop perceived stigma than those patients who had less than one year duration of illness. Those patients who had 6-10 years duration of illness were more than four times [(AOR $=4.29, \mathrm{CI}: 1.90,9.68)$ ] more likely to develop perceived stigma than those patients who had less than one year duration of illness and those patients who had duration of illness greater than or equal to eleven year were more than four times $(\mathrm{AOR}=4.31, \mathrm{CI}: 1.86,10.00)$ more likely to develop perceived stigma than those patients who had less than one year duration of illness. These results were consistent with the previous studies ${ }^{28}$. This may be due to the chronicity of the illness, lack of coping strategies to different seizure effect such as perceived negative social attitude as a result of unaccepted sign of seizure, or the subjects may not develop stigma resistance ability through their life that help them to cope up with different cultural belief, social stigma and the impact of the illness that contributed to perceived stigma. This result indicates that those patients who had longer duration of disease in their life had more perceived stigma compared to those who had shorter duration of the disease.

Those patients who had seizure frequency of one and above per months were more than five times [(AOR = 5.63, CI: 3.42, 10.32)] more likely to develop perceived stigma than those patients who had no seizure frequency and those patients who had seizure frequency of one and above per year were more than two times [(AOR=2.34, CI: 2.24, 3.56)] more likely to develop perceived stigma than those patients who had no seizure frequency. These results were consistent with the previous studies ${ }^{12}$ and a study carried out in Europe also revealed that 45 percent of those patients who experiencing continuing seizures reported perceived stigma ${ }^{29}$. The possible reason may be because of the signs of 
epilepsy are peculiarly unhidden, unpredictable and not easy to understand. These difficulties together with the association of seizure with socially unacceptable sign such as loss of stool, urine, foaming and tongue biting lead epileptic patient to develop stigma. A study carried out in Boston, Massachusetts, and Atlanta, Georgia, also reviled that those patients with longer epilepsy duration, seizures in the past year, and perception of less seizure control and negative expectation for seizures outcomes, decreased patient satisfaction predict perceived stigma ${ }^{28}$.

\section{Strength of the study}

This study is the first of its kind in the study area to show the prevalence of perceived stigma among individuals with epilepsy.

\section{Limitations of the study}

The lack of enough published literature in Ethiopia limits the comparison (discussion) of the findings. Recall and response biases might have occurred when completing the questionnaire. In addition, some of the independent variables were assessed with single questions. For example, difficulties of adherence to their AEDs that may lead some patients to respond indecently.

\section{Conclusion}

Overall, the prevalence of perceived stigma was found to be high. Marital status (single and widowed), long duration of illness and seizure frequency were factors associated with perceived stigma. These findings add important evidence to the existing scant study in subSaharan Africa and other developing countries on the psychological aspect of individual people with epilepsy. Therefore different social relationships (such as befriending programs, family and peer support groups) are recommended particularly for those patients with single and widowed. Building up of patients' stigma resistance ability is also suggested for those who had early onset of the illness and has frequent seizures in the clinical care setting. Additional researches with qualitative and quantitative study methods are also suggested, in order to explore the relationship of socio-demographic and clinical factors.

\section{Competing interests}

The authors declared that there is no competing interest.

\section{Authors' contribution}

Berhanu Boru carried out the manuscript from its con- ception, analysis and interpretation of data and drafted the manuscript. Berihun Assefa participated in reviewing, data analysis, commented and drafted the manuscript. Bewket Tadesse participated in data analysis, interpretation and review of the manuscript. All authors read and approved the final draft of the manuscript.

\section{Acknowledgment}

Authors' gratitude goes to The University of Gondar, Research and Community Service Core Process for financial support. Funder had no role in study design, data collection, analysis and decision to publish. We would like to thanks the study subjects for their willingness to participate in the study. Last but not least our heartfelt thanks go to the supervisors and data collectors for their admirable endeavor during the data collection.

\section{References}

1. Ngugi, A. K., Bottomley, C., Kleinschmidt, I., Sander, J. W., \& Newton, C. R. (2010). Estimation of the burden of active and life-time epilepsy: A meta-analytic approach. Epilepsia 2010; 51 (5), 883-890. doi:10.1111 /j.1528-1167.2009.02481.

2. WHO. EPILEPSY IN THE WHO AFRICAN REGION: Bridging the Gap, The Global Campaign Against Epilepsy "Out of the Shadows". 2004.

3. Bagley C. 3. Social prejudice and the adjustment of people with epilepsy. Epilepsia. 1972;13:33-45. doi: 10.1111/j.1528-1157.1972.tb04547.

4. Teklehaimanot R, Abebe M, Forsgren L, Gebremariam A, Heijbel J, Holmgren G et al. Attitudes of Rural People in Central Ethiopia Toward Epilepsy. Social Science \& Medicine 1991;32 (2):203-9.

5. Tekle-Haimanot R, Abebe M, Gebre-Mariam A, Forsgren L, Heijbel J, Holmgren G, et al. Community-based study of neurological disorders in rural central Ethiopia. Neuroepidemiology. 1990;9:263-77.

6. E G. Notes on the management of a spoiled identity. Engelwood Cliffs: Prentice-Hall Inc. 1963.

7. Werner P A, A., \& Barak, Y. Self-stigma, self-esteem and age in persons with schizophrenia. International Psychogeriatrics. 2008;20(1):174-87.

8. Corrigan P KA KL. The stigma of mental illness explanatory models and methods for change Applied \& Preventive Psychology. 2005;11(3):179-90.

9. Sheer AA. Depression among Epileptic Patients in Governmental Community Mental Health Centers in Gaza Strip. The Islamic University - Gaza Faculty of Nursing - Education Deanery of Higher Education. 
10. Kanitpong MD, Suwanna, M.D., Ponchai, M.D. \& Kitti, M.D. Anxiety and depression in Thai epileptic patients. J Med Assoc Thai. 2007;90(10):2010-5. http:// www.medassocthai.org/journal.

11. Florentina Rafael ea. Houinato. Sociocultural and psychological features of perceived stigma reported by people with epilepsy in Benin Neorology. 2010;51(6):106186. doi: $10.1111 /$ j.1528- 1167.2009.02511.x.

12. Teshome Shibre, Atalay Alem, Redda TekleHaimanot, Girmay Medhin and Lars Jacobsson. Perception of stigma among family members of patients epilepsy and their relatives in Butajira, Ethiopia. Ethiop J Health Dev. 2006;20(3):170-6.

13. Baker G BJ, Buck D, Jacoby A. The Stigma of Epilepsy: A European Perspective. Epilepsia 1999;41(1):98104.

14. Intisar A. G. Khudhur FJM. Impact of epilepsy on patient's physical and psychosocial functioning Iraqi study. Health Science Journal. 2012;6(3).

15. Shitaye Almu ZT, Paul Cooper, Richard Hackett. The prevalence of epilepsy in the Zay Society, Ethiopia an area of high prevalence Elsevier. 2006.

16. Shibru Berhanu SA, Jilalu Asmera and Martin Prevett. Primary care treatment of epilepsy in Rural Ethiopia. Ethiop J Health Dev. 2002;16(3):235-40.

17. FDROEMO H. National Mental Health Strategy 2012/13- 2015/16, Federal Democratic Republic of Ethiopia Ministry of Health. Addis Ababa: 2012.

18. Sartorius N aJA. Psychiatric assessment instruments developed by the World Health Organization. Soc Psychiatry Epidemiology 1996;31 (2):55-9.

19. Jones JE HB, Woodard JL, Barry JJ, Gilliam F, Kanner AM, Meador KJ. Screening for major depression in epilepsy with common self-report depression inventories. Epilepsia. 2005;46:731-5.

20. Sang-Ahm Lee S-ML, and Young-Joo No. Fac- tors contributing to depression in patients with epilepsy. Epileps. 2010;51(7):1305-8. doi: 10.1111/j.15281167.2009.02387.x.

21. Cohen S, Kamarck T, Mermelstein R. A global measure of perceived stress. Journal of Health and Social Behavior. 1983;24:386-96. doi: 10.2307/2136404.

22. Kleinman A WW, Li SC, et al. The social course of epilepsy: chronic illness as social experience in interior China. Social Science \& Medicine. 1995;40:1319-30.

23. A Oun, S Haldre, S Haldre, S Haldre. Felt stigma and impact of epilepsy on employment status among Estonian people: exploratory study. Seizure 2000;9:394401. DOI: $10.1053 /$ seiz.2000.0439.

24. Reddy PV. Prevalence of depression among epileptic patients . Indian Journal of Applied Research 2012;4 (1):424-7.

25. Agarwal P MM, Antony AR, Kumar N, Dwivedi RN, Sharma P, Kumar S. Epilepsy in India: nuptiality behaviour and fertility. Seizure 2006;15 (6):409-15.

26. Hamidreza Riasi ARS, and Kazem Ghaemi. The stigma of epilepsy and its effects on marital Status. Springer Plus. 2014;3:762. doi: 10.1186/2193-1801-3-762.

27. Bhalla D, Chea K, Hun C, Vannareth M, Huc P, Chan S, Sebbag R, Gerard D, Dumas M, Oum S, Druet-Cabanac M, Preux PM. (2012) Populationbased study of epilepsy in cambodia associated factors, measures of impact, stigma, quality of life, knowledge-attitudepractice, and treatment gap. PLoS One.2012; 7:1-9. doi: 10.1371/journal.pone.0046296. Epub 2012 Oct 15.

28. DiIorio C SP, Letz R, Henry T, Schomer DL, Yeager $\mathrm{K}$. The association of stigma with self- management and perceptions of health care among adults with epilepsy. Epilepsy and Behavior. 2003;4:259-67.

29. Baker GA JA, Buck D, Stalgis C, Monnet D. Quality of life of people with epilepsy: a European study. Epilepsia 1997;38:353-62. http://dx.doi.org/10.1590/ S1676-2649200700040000 